\title{
InfluênCia do Resíduo de Colheita de Cana-de-Açúcar Sem QUEIMA SOBRe A EFICIÊNCIA dOS HERBICIDAS IMAZAPIC E IMAZAPIC + Pendimethalin ${ }^{1}$
}

\author{
Sugar-Cane Harvest Residue Influence on the Efficacy of the Herbicides Imazapic and \\ Imazapic + Pendimethalin
}

HERNANDEZ, D.D. ${ }^{2}$, ALVES, P.L.C.A. ${ }^{3}$ e MARTINS, J.V.F. ${ }^{4}$

\begin{abstract}
RESUMO - Os resíduos deixados sobre o solo por ocasião da colheita mecanizada da cana-deaçúcar podem constituir-se em uma barreira física para a ação dos herbicidas no controle de plantas daninhas, quando aplicados em pré-emergência destas plantas sobre a palha da cana. Em virtude disso, o presente trabalho teve por objetivos analisar e quantificar a interferência dessa camada de palha sobre o solo na ação dos herbicidas imazapic e imazapic + pendimethalin no controle de plantas daninhas em áreas onde a cana-de-açúcar foi colhida mecanicamente sem a queima da palhada previamente à colheita. Foram realizados dois ensaios simultâneos: um com a retirada da palha dois dias após a aplicação dos herbicidas e o outro com a manutenção desta, ambos conduzidos em casa de vegetação. O imazapic isolado foi aplicado nas dosagens de $0,122,5$ e $147 \mathrm{~g}$ i.a.ha ${ }^{-1}$ e em mistura com pendimethalin na dosagem de 75 + 1500 g i.a.ha ${ }^{-1,}$ com simulação de chuvas nas intensidades de 30,60 e $90 \mathrm{~mm}$. Após análise dos resultados de biomassa seca, altura e número de folhas das plantas de Sorghum bicolor e Cyperus rotundus, além de nota visual e biomassa seca de Panicum maximum, Brachiaria plantaginea, Digitaria horizontalis, Amaranthus viridis, Ipomoea grandifolia e Brachiaria decumbens, constatou-se eficiência proporcional dos herbicidas à dosagem utilizada, independentemente da presença da palha, à exceção de Ipomoea grandifolia e Brachiaria decumbens, além de haver menor controle nos tratamentos submetidos à chuva de $90 \mathrm{~mm}$. Esses resultados indicam boas perspectivas quanto à aplicação destes herbicidas em áreas de colheita mecanizada de cana-de-açúcar sem queima, para controle de plantas daninhas em condições de pré-emergência.
\end{abstract}

Palavras-chave: palhada, barreira física, colheita mecanizada.

\begin{abstract}
The residues left on the soil surface after sugarcane automated harvest, without previous slash-and-burn, constitute a physical barrier against the action of herbicides applied at pre-emergence conditions of the weeds. Thus, this research aimed to analyze and quantify the interference of this crop residue layer left on the soil surface in the action of the herbicides imazapic and imazapic + pendimethalin to control weeds. Two simultaneous assays were performed: one by removing the crop residue two days after herbicide application and the other by maintaining it, both conducted under greenhouse conditions. The imazapic was applied at the rates of $0,122.5$ and $147 \mathrm{~g}$ a.i. $h \mathrm{a}^{-1}$ and the mixture with pendimethalin at the a rate of $75+$ $1500 \mathrm{~g}$ a.i. ha ${ }^{1}$, with simulation of 30, 60 and $90 \mathrm{~mm}$ rainfall intensity. Analysis of dry biomass, height and leaf number results of the Sorghum bicolor and Cyperus rotundus plants, as well as visual rating and dry biomass of Panicum maximum, Brachiaria plantaginea, Digitaria horizontalis, Amaranthus viridis, Ipomoea grandifolia and Brachiaria decumbens, indicated that weed control efficacy was proportional to herbicide rate, regardless of the presence of crop residue, except for Ipomoea grandifolia and Brachiaria decumbens. There was less control in the treatments submitted to $90 \mathrm{~mm}$ rainfall. These results indicate good perspectives in spraying these herbicides in sugarcane automated harvest areas without previous slash-andburn for weed pre emergence control.
\end{abstract}

Key words: percolation, straw, physical barrier, automated harvest.

Recebido para publicação em 18/4/2001 e na forma revisada em 17/12/2001.

2 Acadêmico de Agronomia e estagiário do DBAA/FCAV-UNESP, Jaboticabal-SP, <donatohe @ fcav.unesp.br>; ${ }^{3}$ Eng ${ }^{\circ}$.-Agrônomo, Dr., Professor Assistente Doutor do DBAA/FCAV-UNESP. Rod. Prof. Paulo Donato Castellane, s/n, 14884-900 Jaboticabal-SP, <plalves@fcav.unesp.br>; ${ }^{4}$ Auxiliar Técnico do DBAA/FCAV-UNESP, Jaboticabal-SP.

Planta Daninha, Viçosa-MG, v.19, n.3, p.419-426, 2001 


\section{INTRODUÇÃO}

A cana-de-açúcar (Saccharum spp.), originária da Índia, está disseminada em todo o mundo, numa faixa compreendida entre os paralelos $22^{\circ}$ ao norte e ao sul do Equador. Atualmente, a cultura da cana, por seu valor energético, é considerada uma das mais importantes explorações agrícolas do globo terrestre.

O Brasil, por sua vez, é o maior produtor mundial de açúcar, forte elemento na geração de divisas, por meio da exportação. A área colhida foi, em 2000, de aproximadamente 4,8 milhões de hectares, com produção em torno de 324.457.000 toneladas de colmos (Agrianual, 2001). O País domina a tecnologia de produção de álcool etílico, combustível responsável pela significativa diminuição de petróleo, além de ser menos prejudicial ao ambiente.

Dessa forma, é necessária a implantação de novas técnicas que permitam o aumento de produtividade da cultura. Essas técnicas devem atuar sobre os fatores que afetam significativamente a produtividade, como as variedades e adubações adequadas, a irrigação e o controle de pragas, doenças, nematóides e plantas daninhas.

Como em qualquer outra cultura, a infestação de plantas daninhas é uma séria ameaça à produtividade da cana-de-açúcar e chega a reduzi-la em até 86\% (Lorenzi, 1983), dependendo do grau de infestação e da espécie infestante. As reduções na produção de colmos em cana-soca, citadas por Lorenzi (1986), são de $22 \%$ no Brasil, $75 \%$ na Argentina, 38\% na Austrália e 85\% na África do Sul. Kuva et al. (2000) observaram que a presença de uma comunidade de plantas daninhas e de plantas de cana-de-açúcar em um ambiente comum implicou uma série de efeitos bidirecionais, denominados interferência. A interferência das plantas daninhas é bastante ampla e corresponde ao conjunto de ações positivas e negativas que sofre uma determinada cultura em decorrência das plantas daninhas. Estas plantas interferem negativamente na cultura da cana-de-açúcar, por liberar substâncias alelopáticas, hospedar pragas e moléstias que atacam a cultura, dificultar práticas culturais e colheita, depreciar o produto e, principalmente, competir por fatores limitantes do meio (particularmente água, luz e nutrientes).
A infestação de plantas daninhas no canavial pode provocar reduções diretas na produção, decorrentes da competição por elementos vitais; da ação alelopática; da redução do valor comercial, devido à presença de seus restos na carga de cana levada à usina; e da redução do rendimento na colheita. As plantas daninhas podem ainda reduzir a produção de cana-de-açúcar indiretamente, por serem hospedeiros intermediários de insetos, doenças, vírus e nematóides (Lorenzi, 1983).

A intensidade e o balanço da interferência entre a cana-de-açúcar e a comunidade infestante dependem de fatores ligados à própria cultura, como a variedade utilizada, densidade e distribuição dos indivíduos na área cultivada, e de fatores ambientais, como variações climáticas e edáficas. Além disso, depende do tempo e da época em que a cultura e a comunidade infestante estiveram em convivência (Pitelli, 1985). De maneira geral, pode-se dizer que, quanto maior for o período de convivência múltipla - comunidade infestante e cultura -, maior será o grau de interferência.

Atualmente, o principal método de controle das plantas daninhas é por meio de aplicações de herbicidas (controle químico), tanto na pré como na pós-emergência dessas plantas. O comportamento de um herbicida no solo é influenciado por processos de retenção, transformação e transporte, que ocorrem imediata e/ou simultaneamente após a sua aplicação (Weber \& Miller, 1989).

Os atributos do solo que mais influenciam o movimento descendente dos herbicidas são o conteúdo de matéria orgânica, a composição e a distribuição do tamanho das partículas do solo, o pH, a densidade aparente e o tamanho e a distribuição dos poros. Para os herbicidas de elevada capacidade adsortiva, o conteúdo de matéria orgânica é geralmente o fator mais importante, pois, quanto mais alto, menor a lixiviação (Sprankle et al., 1975). A lixiviação será ainda maior em solos de textura arenosa que em solos siltosos ou argilosos (Nicholls, 1988). Para algumas imidazolinonas, como é o caso do imazapic, o tipo de argila, o conteúdo de óxidos e o pH influenciam a sua adsorção e, conseqüentemente, a sua lixiviação (Wehtje et al., 1987; Carlisle \& Trevors, 1988).

Atendendo a uma solicitação da sociedade, as áreas de colheita mecanizada têm aumentado 
anualmente; como conseqüência, cada vez mais extensas áreas estão sendo cobertas pela palha resultante desse processo.

Segundo Arévalo e Bertoncini (1999), os resíduos da colheita mecanizada de cana-deaçúcar controlam normalmente mais de 50\% das plantas que infestam a cultura. Esse controle está ligado à quantidade de resíduos, à densidade destes e à distribuição no campo.

Embora o solo esteja coberto com uma camada de palha, sabe-se que determinadas espécies de plantas daninhas, ao germinarem, vão vencer essa barreira física e vão se estabelecer no canavial, onde exercerão sua interferência, o que pode ser resultado do fato de alguns herbicidas serem mais retidos na cobertura e outros, menos. Devido a isso, Fornarolli et al. (1998) afirmam que há necessidade de aumentar as dosagens dos herbicidas para compensar as perdas, evitando-se com isso redução da eficiência de controle.

Diante do exposto, este trabalho teve o objetivo de avaliar a influência da palha de cana-de-açúcar sobre a eficiência do herbicida imazapic, isolado e em mistura com pendimethalin, no controle de plantas daninhas.

\section{MATERIAL E MÉTODOS}

Foram instalados dois experimentos em casa de vegetação pertencente ao Departamento de Biologia Aplicada à Agropecuária da Faculdade de Ciências Agrárias e Veterinárias - UNESP - Jaboticabal, SP. No primeiro experimento, a palha foi retirada 48 horas após a aplicação dos herbicidas, enquanto no segundo esta foi deixada até o término do período experimental.

Os tratamentos do primeiro e do segundo experimento encontram-se descritos nas Tabelas 1 e 2, respectivamente.

Para a aplicação dos herbicidas, usou-se pulverizador costal de pressão constante (ar comprimido), munido de barra com quatro bicos do tipo XR 110-02, com volume de calda de 200 L.ha $^{-1}$.

Os tratamentos experimentais nos dois ensaios foram dispostos no delineamento inteiramente casualizado; no primeiro experimento foram utilizadas três repetições e, no segundo, quatro.
Tabela 1 - Descrição dos tratamentos experimentais utilizados no primeiro experimento. Jaboticabal-SP, 2000

\begin{tabular}{|l|c|c|}
\hline \multicolumn{1}{|c|}{ Tratamentos } & $\begin{array}{c}\text { Dosagens } \\
\left(\mathrm{g} \mathrm{i.a.} \mathrm{ha}^{-1}\right)\end{array}$ & $\begin{array}{c}\text { Chuva } \\
(\mathrm{mm})\end{array}$ \\
\hline 1 - imazapic sobre a palha & 122,5 & 30 \\
2 - imazapic sobre a palha & 122,5 & 60 \\
3 - imazapic sobre a palha & 122,5 & 90 \\
4 - imazapic sobre a palha & 147,0 & 30 \\
5 - imazapic sobre a palha & 147,0 & 60 \\
6 - imazapic sobre a palha & 147,0 & 90 \\
7 - imazapic sobre o solo & 122,5 & 60 \\
8 - imazapic + pendimethalin sobre a palha & $75+1500$ & 90 \\
9 - testemunha sem aplicação & 0,0 & 0,0 \\
\hline
\end{tabular}

Tabela 2 - Descrição dos tratamentos experimentais utilizados no segundo experimento. Jaboticabal-SP, 2000

\begin{tabular}{|l|c|c|}
\hline \multicolumn{1}{|c|}{ Tratamentos } & $\begin{array}{c}\text { Dosagens } \\
\left(\mathrm{g} \mathrm{i.a.} \mathrm{ha}^{-1}\right)\end{array}$ & $\begin{array}{c}\text { Chuva } \\
(\mathrm{mm})\end{array}$ \\
\hline 1 - testemunha sem palha & 0,0 & 0,0 \\
2 - imazapic sobre o solo & 122,5 & 30 \\
3 - imazapic sobre a palha & 122,5 & 30 \\
4 - imazapic + pendimethalin sobre a palha & $75+1500$ & 30 \\
5 - testemunha com palha & 0,0 & 0,0 \\
\hline
\end{tabular}

O primeiro experimento foi realizado em tubo de PVC com capacidade para 35 litros $(0,3 \mathrm{~m}$ de diâmetro por $0,5 \mathrm{~m}$ de altura), preenchido com um Latossolo Vermelho-Escuro (LE), cujas características físico-químicas encontram-se na Tabela 3, no qual se plantaram quatro tubérculos de tiririca (CYPRO) e 10 sementes de sorgo (Sorghum bicolor) por tubo, a $2 \mathrm{~cm}$ de profundidade. Na seqüencia, na superfície deste, foi colocada palha de cana-de-açúcar (var. SP79 1011) picada em fragmentos de $5 \mathrm{~cm}$ de comprimento, em média, em quantidade equivalente a $12 \mathrm{t} \mathrm{ha}^{-1}$, sendo o sistema umedecido. Aplicaram-se os herbicidas nos tubos e, 24 horas após, simulou-se manualmente, por meio de regador de plástico, a chuva correspondente a cada tratamento. Ao término da simulação, cerca de 48 horas após a aplicação, retirou-se a palhada. Aos 30 dias após a aplicação (30 DAA), foram realizadas as determinações de número de folhas, altura e biomassa seca das plantas de tiririca e de sorgo. Para acompanhar visualmente a movimentação do herbicida no perfil do solo, nessa ocasião, um tubo correspondendo a uma repetição de cada tratamento foi aberto longitudinalmente e, em cada perfil do solo contido nas duas metades, foram semeadas 10 sementes de 
sorgo a cada $5 \mathrm{~cm}$ de profundidade, iniciandose esta semeadura a $0,5 \mathrm{~cm}$ da superfície que recebeu a aplicação.

O segundo experimento foi realizado em vaso com capacidade para 5 litros, preenchido com a mesma classe de solo (LE), no qual foi semeada uma medida contendo em média 100 sementes de capim-colonião (PANMA), 20 sementes de capim-marmelada (BRAPL), 20 sementes de capim-braquiária (BRADC), 30 sementes de capim-colchão (DIGHO), 20 sementes de caruru (AMAVI) e 10 sementes de corda-de-viola (IAOGR) e plantados cinco tubérculos de tiririca (CYPRO. Estas sementes foram adquiridas na SHOKUCHO do Brasil Agrícola Ltda (Arthur Nogueira-SP), onde foram submetidas a testes prévios de vigor e germinação. Depois disso, colocou-se palha de canade-açúcar (var. SP79 - 1011) em quantidade equivalente a $12 \mathrm{t} \mathrm{ha}^{-1}$ sobre a superfície dos vasos, também picada, deixando-a até o final do experimento. Na seqüência, foi feita a aplicação dos herbicidas e, 24 horas após, simulouse uma chuva de $30 \mathrm{~mm}$. Ao final do experimento, aos 30 DAA, foi realizada avaliação da eficiência dos tratamentos no controle das plantas daninhas por meio de notas visuais, conforme a escala da ALAM (1974), e determinou-se a biomassa seca das plantas daninhas.

Os resultados obtidos foram submetidos à análise de variância pelo teste $\mathrm{F}$ e, quando significativas, as médias foram comparadas pelo teste de Tukey a 5\% de probabilidade.

\section{RESULTADOS E DISCUSSÃO}

No primeiro experimento, observou-se que todos os tratamentos em que se empregou imazapic isoladamente ou em mistura com pendimethalin causaram redução na altura das plantas de tiririca e sorgo, quando comparados à testemunha sem aplicação (Tabela 4). A maior altura das plantas de tiririca nos tratamentos com imazapic (tratamento 3) foi $75 \%$ menor quando comparada à da testemunha, e a maior altura das plantas de sorgo nos tratamentos com herbicida (tratamento 6) foi $68 \%$ menor quando comparada com a testemunha.

Verificou-se que a quantidade de chuva simulada sobre a palha afetou o desempenho do herbicida. No caso da altura das plantas de tiririca, esse efeito não foi significativo, mas se observou tendência de plantas mais altas quando sob chuva de $90 \mathrm{~mm}$ quando comparadas às de $30 \mathrm{~mm}$, independentemente da dosagem de herbicida utilizada. Nas plantas de sorgo essa tendência também se manteve, e, no caso da dosagem de 147 g i.a. ha ${ }^{-1}$, as plantas sob chuva de $90 \mathrm{~mm}$ mostraram-se significativamente mais altas que as de $30 \mathrm{~mm}$. A ausência da palha, quando na dosagem de 122,5 g.i.a.ha ${ }^{-1}$ e com uma chuva de $60 \mathrm{~mm}$ (tratamento 7), proporcionou plantas de tiririca e de sorgo de mesma altura, quando comparadas às obtidas sob mesmas condições, porém com palha (tratamento 2), demonstrando que a palha não prejudicou a ação do produto. No caso desta forma de aplicação, pode-se observar, por meio da análise visual do perfil do solo dos tubos, que com chuva de $90 \mathrm{~mm}$ o produto percolou para maiores profundidades, deixando de atuar eficientemente na camada superficial (Figura 1), enquanto com chuva de $30 \mathrm{~mm}$ ocorreu o inverso, com o produto atuando com eficiência nos $15 \mathrm{~cm}$ superficiais.

Tabela 3 - Resultados da análise físico-química de uma amostra composta do Latossolo Vermelho-Escuro (LE) utilizado como substrato. Jaboticabal-SP, 2000

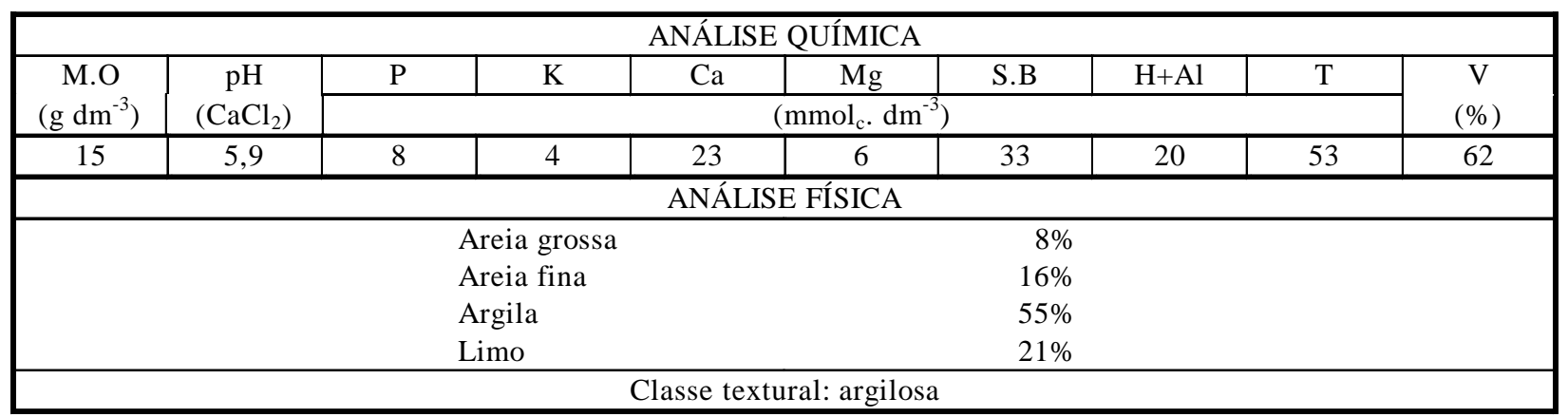


Tabela 4 - Efeito dos tratamentos sobre altura, número de folhas e biomassa seca de tiririca (CYPRO) e sorgo aos 30 DAA. Jaboticabal-SP, 2000

\begin{tabular}{|c|c|c|c|c|c|c|c|c|}
\hline \multicolumn{3}{|c|}{ Tratamentos } & \multicolumn{3}{|c|}{ CYPRO } & \multicolumn{3}{|c|}{ SORGO } \\
\hline Descrição & $\begin{array}{l}\text { Dosagem } \\
\left(\text { g.i.a.ha }{ }^{-1}\right)\end{array}$ & $\begin{array}{c}\text { Chuva } \\
(\mathrm{mm})\end{array}$ & $\begin{array}{l}\text { Altura } \\
(\mathrm{cm})\end{array}$ & № Folhas ${ }^{2 /}$ & $\begin{array}{c}\text { Biomassa Seca } \\
(\mathrm{g})\end{array}$ & $\begin{array}{c}\text { Altura } \\
(\mathrm{cm})\end{array}$ & $\mathrm{N}^{\mathrm{o}}$ Folhas & $\begin{array}{c}\text { Biomassa Seca } \\
(\mathrm{g})\end{array}$ \\
\hline 1) Imazapic sobre palha & 122,5 & 30 & $0,00 \mathrm{~B}^{1 /}$ & $0,0 \mathrm{~B}$ & $0,000 \mathrm{~B}$ & $0,83 \mathrm{D}$ & $1,5 \mathrm{~B}$ & $0,000 \mathrm{D}$ \\
\hline 2) Imazapic sobre palha & 122,5 & 60 & $0,00 \mathrm{~B}$ & $0,0 \mathrm{~B}$ & $0,000 \mathrm{~B}$ & $1,23 \mathrm{BCD}$ & $1,6 \mathrm{~B}$ & $0,120 \mathrm{BCD}$ \\
\hline 3) Imazapic sobre palha & 122,5 & 90 & $2,00 \mathrm{~B}$ & $2,1 \mathrm{~A}$ & $0,007 \mathrm{~B}$ & $1,47 \mathrm{BCD}$ & $1,7 \mathrm{~B}$ & $0,197 \mathrm{~B}$ \\
\hline 4) Imazapic sobre palha & 147,0 & 30 & $0,17 \mathrm{~B}$ & $0,6 \mathrm{~B}$ & $0,000 \mathrm{~B}$ & $1,00 \mathrm{CD}$ & $1,5 \mathrm{~B}$ & $0,033 \mathrm{CD}$ \\
\hline 5) Imazapic sobre palha & 147,0 & 60 & $0,33 \mathrm{~B}$ & $0,5 \mathrm{~B}$ & $0,003 \mathrm{~B}$ & $1,33 \mathrm{BCD}$ & $1,6 \mathrm{~B}$ & $0,130 \mathrm{BC}$ \\
\hline 6) Imazapic sobre palha & 147,0 & 90 & $1,40 \mathrm{~B}$ & $1,9 \mathrm{~A}$ & $0,047 \mathrm{~B}$ & $1,77 \mathrm{~B}$ & $1,7 \mathrm{~B}$ & $0,197 \mathrm{~B}$ \\
\hline 7) Imazapic sobre solo & 122,5 & 60 & $1,50 \mathrm{~B}$ & $2,1 \mathrm{~A}$ & $0,003 \mathrm{~B}$ & $1,53 \mathrm{BC}$ & $1,7 \mathrm{~B}$ & $0,010 \mathrm{CD}$ \\
\hline $\begin{array}{l}\text { 8) Imazapic + pendimethalin } \\
\text { sobre palha }\end{array}$ & $75+1500$ & 90 & $1,47 \mathrm{~B}$ & $2,1 \mathrm{~A}$ & $0,010 \mathrm{~B}$ & $1,23 \mathrm{BCD}$ & $1,7 \mathrm{~B}$ & $0,093 \mathrm{BCD}$ \\
\hline 9) Testemunha sem aplicação & 0,0 & 0,0 & $7,90 \mathrm{~A}$ & $2,7 \mathrm{~A}$ & $1,530 \mathrm{~A}$ & $4,83 \mathrm{~A}$ & $2,2 \mathrm{~A}$ & $2,927 \mathrm{~A}$ \\
\hline \multicolumn{3}{|l|}{$\mathrm{F}$ (trat.) } & $36,51^{* *}$ & $15,17 * *$ & $11,56^{* *}$ & $82,95^{* *}$ & $18,03 * *$ & $1503,49 * *$ \\
\hline \multicolumn{3}{|l|}{ DMS } & 2,02 & 1,34 & 0,74 & 0,66 & 0,22 & 0,12 \\
\hline \multicolumn{3}{|l|}{$\mathrm{CV}(\%)$} & 43,10 & 35,17 & 145,36 & 13,60 & 4,46 & 10,26 \\
\hline
\end{tabular}

1/ Médias seguidas por mesma letra, na coluna, não diferem entre si pelo teste de Tukey a 5\% de probabilidade.

$*$, **: Significativo a 5 e $1 \%$ de probabilidade pelo teste $\mathrm{F}$, respectivamente.

2l Dados transformados para $\sqrt{n^{\mathrm{o}}}$.

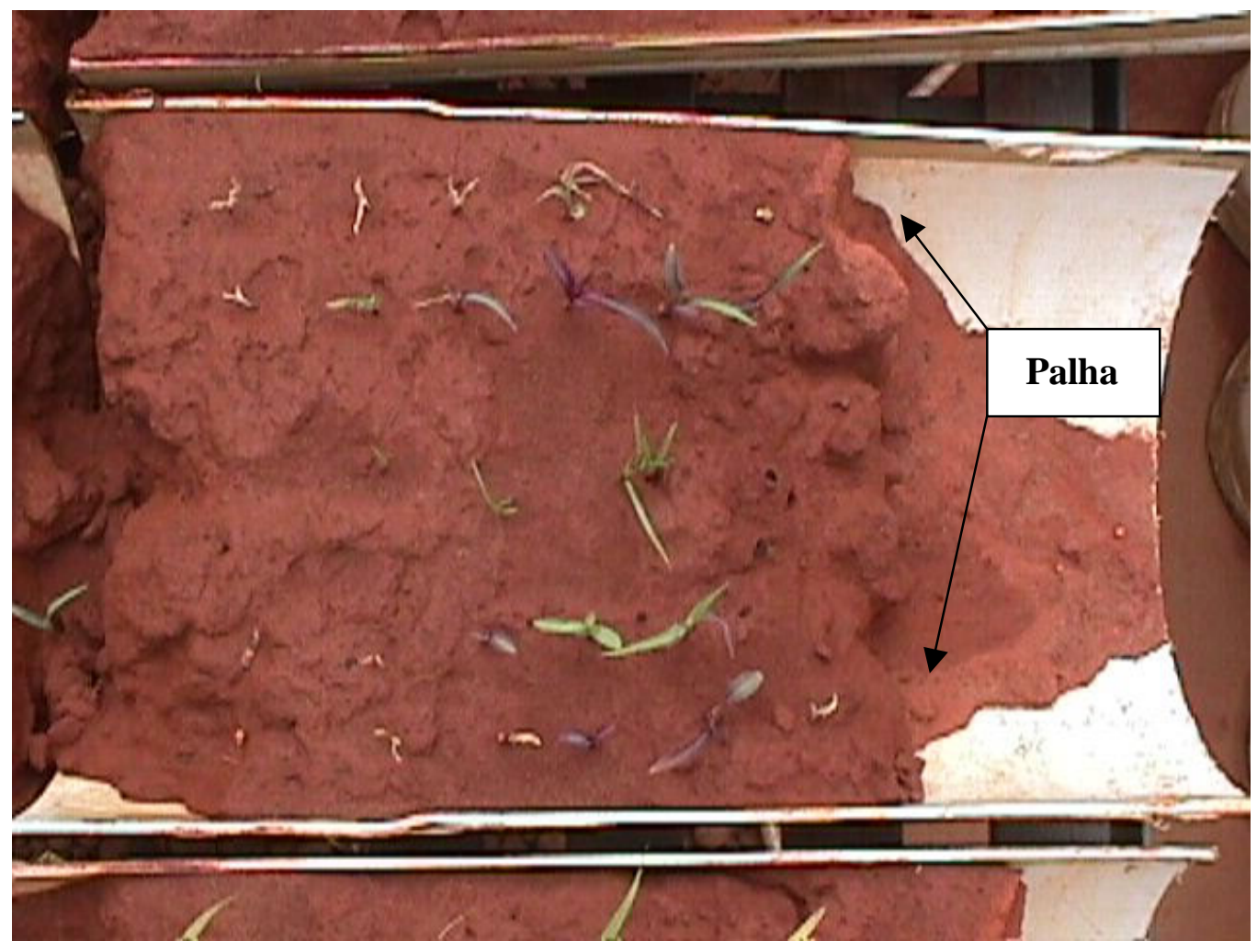

Figura 1 - Detalhe de um dos lados do tubo aberto, com a indicação do local onde havia palha de cana-de-açúcar, mostrando o arraste do produto para maiores profundidades em razão de uma chuva simulada de $90 \mathrm{~mm}$, onde causou redução na altura das plantas de sorgo e de tiririca. 
A mistura de imazapic e pendimethalin (tratamento 8), quando aplicada sobre a palha e submetida a chuva de $90 \mathrm{~mm}$, atuou de maneira semelhante à dos demais tratamentos, embora tenha apresentado tendência de proporcionar plantas de sorgo menores que as obtidas com o produto isolado, nas duas dosagens, e submetidas à mesma chuva (tratamentos 3 e 6). Rodrigues et al. (2000) observaram que o herbicida imazaquin, uma imidazolinona tal qual o imazapic, arrastou-se através da palha a partir de uma chuva igual a $20 \mathrm{~mm}$, ao passo que, antes de se efetuar a irrigação, mais de $90 \%$ desse produto aplicado permanecia sobre a palha. O arraste desses produtos pela água pode ser explicado pela sua alta solubilidade em água (Rodrigues \& Almeida, 1998). Fornarolli et al. (1998) verificaram que 85\% da dosagem aplicada do herbicida atrazine, uma triazina, ficou retida na cobertura morta, sendo esta arrastada através da palha somente após uma irrigação equivalente a $20 \mathrm{~mm}$.

Com relação ao número de folhas de tiririca, verificou-se que apenas quando a chuva foi de até $60 \mathrm{~mm}$ sobre as dosagens de 122,5 e 147 g i.a. ha ${ }^{-1}$ houve redução nessa característica (Tabela 4). A chuva de $90 \mathrm{~mm}$ sobre o imazapic isolado ou em mistura com pendimethalin não afetou o número de folhas de tiririca; o mesmo ocorreu quando o produto foi aplicado sobre o solo nu e, em seguida, submetido a uma chuva de $60 \mathrm{~mm}$. Esse resultado demonstra novamente que a chuva simulada de $90 \mathrm{~mm}$ afeta a eficiência do produto. No caso das plantas de sorgo, todas as dosagens do produto isolado ou em mistura com pendimethalin proporcionaram redução no número de folhas, independentemente do índice pluviométrico.

No que refere à biomassa seca das plantas de tiririca (Tabela 4), verificou-se que todas as dosagens do imazapic isolado ou em mistura com pendimethalin proporcionaram redução nessa característica, independentemente do indice pluviométrico. No caso particular dos tratamentos 3 e 6 , que correspondem à chuva de $90 \mathrm{~mm}$ sobre as dosagens de $122,5 \mathrm{e}$ $147 \mathrm{~g}$ i.a. ha ${ }^{-1}$, respectivamente, e dos tratamentos que envolveram a aplicação do produto em mistura com pendimethalin ou dele isolado sobre o solo nu (tratamentos 7 e 8), pode-se afirmar que os tubérculos brotaram e emitiram manifestações epígeas com o mesmo número de folhas da testemunha, porém não cresceram em altura e nem acumularam biomassa seca.

No segundo ensaio, quando se deixou a palha sobre o solo até o término do período experimental, pode-se observar que os tratamentos com imazapic isolado ou em mistura com pendimethalin proporcionaram controle de muito bom a excelente para todas as espécies daninhas, independentemente da presença da palha ou não, com exceção do capim-braquiária (BRADC), que apresentou, segundo ALAM (1974), nenhum controle para os tratamentos com imazapic isolado e controle bom para o imazapic misturado ao pendimethalin (Tabela 5). Comparando as duas testemunhas (tratamentos 1 e 5), pode-se observar que a cobertura morta do solo com palha causou redução na densidade de todas as espécies de plantas daninhas postas para germinar, à exceção da tiririca (CYPRO) e da corda-de-viola (IAOGR), para as quais a cobertura com palha proporcionou aumento na densidade.

Tabela 5 - Densidade específica de plantas por vaso, com nota visual de controle segundo a escala ALAM, e porcentagem de controle geral, ambos aos 30 dias após a aplicação. Jaboticabal-SP, 2000. Média de quatro repetições

\begin{tabular}{|l|c|c|c|c|c|c|c|c|c|c|}
\hline \multirow{2}{*}{ Espécies } & \multicolumn{2}{c|}{ Tratamento 1 } & \multicolumn{2}{c|}{ Tratamento 2 } & \multicolumn{2}{c|}{ Tratamento 3 } & \multicolumn{2}{c|}{ Tratamento 4 } & \multicolumn{2}{c|}{ Tratamento 5 } \\
\cline { 2 - 11 } & Densidade & Nota & Densidade & Nota & Densidade & Nota & Densidade & Nota & Densidade & Nota \\
\hline PANMA & 68,5 & 1 & 0 & 6 & 0 & 6 & 0 & 6 & 53,2 & 1 \\
BRAPL & 13,5 & 1 & 0 & 6 & 0 & 6 & 0 & 6 & 10 & 1 \\
DIGHO & 17,5 & 1 & 0 & 6 & 0 & 6 & 0 & 6 & 9 & 1 \\
AMAVI & 11,7 & 1 & 0 & 6 & 0 & 6 & 0 & 6 & 2 & 1 \\
CYPRO & 4 & 1 & 0 & 6 & 0 & 6 & 0 & 6 & 5,2 & 1 \\
IAOGR & 3,8 & 1 & 0 & 6 & 0,5 & 5 & 0,5 & 5 & 6,2 & 1 \\
BRADC & 5 & 1 & 16,7 & 1 & 5 & 1 & 1,2 & 4 & 0,5 & 4 \\
Controle Geral & 0 & 1 & 96 & 6 & 98 & 6 & 98 & 6 & 0 & 1 \\
\hline
\end{tabular}

Trat. $1=$ testemunha sem palha; Trat. $2=$ imazapic a 122,5 g i.a. ha ${ }^{-1}$ sobre o solo; Trat. $3=$ imazapic a 122,5 g i.a. ha ${ }^{-1}$ sobre a palha; Trat. $5=$ imazapic + pendimethalin a $75+1.500 \mathrm{~g}$ i.a. ha ${ }^{-1}$ sobre a palha; Trat. $5=$ testemunha com palha. 
Tabela 6 - Efeito dos tratamentos sobre a biomassa total e específica das plantas daninhas, com o respectivo controle, em porcentagem e notas visuais, segundo ALAM (1974), no segundo experimento, aos 30 dias após a aplicação. Jaboticabal-SP, 2000

\begin{tabular}{|l|c|c|c|c|}
\hline \multirow{2}{*}{ Tratamento } & \multicolumn{2}{c|}{ Biomassa } & \multicolumn{2}{c|}{ Controle } \\
\cline { 2 - 5 } & $\begin{array}{c}\text { Total } \\
(\mathrm{g})\end{array}$ & $\begin{array}{c}\text { Específica } \\
(\mathrm{g} / \mathrm{planta})\end{array}$ & Porcentagem & Nota Visual \\
\hline 1. Test. sem palha & $3,250 \mathrm{~A}^{\underline{1}}$ & $0,026 \mathrm{~A}$ & $0,0 \mathrm{~B}$ & 0 \\
2. Imazapic sobre o solo & $0,025 \mathrm{~B}$ & $0,001 \mathrm{~B}$ & $79,0 \mathrm{~A}$ & 4 \\
3. Imazapic sobre a palha & $0,020 \mathrm{~B}$ & $0,002 \mathrm{~B}$ & $81,4 \mathrm{~A}$ & 5 \\
4. Imazapic + pendimethalin sobre a palha & $0,010 \mathrm{~B}$ & $0,003 \mathrm{~B}$ & $83,6 \mathrm{~A}$ & 6 \\
5. Test. com palha. & $3,225 \mathrm{~A}$ & $0,039 \mathrm{~A}$ & $0,0 \mathrm{~B}$ & 0 \\
\hline F trat. & $27,55 * *$ & $16,02 * *$ & $768,46 * *$ & \\
CV\% & 51,44 & 60,13 & 6,6 & \\
DMS & 1,47 & 0,02 & & \\
\hline
\end{tabular}

${ }^{1 /}$ Médias seguidas de mesma letra não diferem entre si a $5 \%$ de probabilidade pelo teste de Tukey.

** Significativo a $1 \%$ de probabilidade pelo teste $\mathrm{F}$.

O fato de a palha sobre o solo dificultar a germinação de plantas daninhas também foi observado por Rodrigues et al. (2000), os quais verificaram que o controle do capim-marmelada (Brachiaria plantaginea) proporcionado por $7 \mathrm{t} \mathrm{ha}^{-1}$ de palha sem aplicação de qualquer herbicida assemelhou-se ao controle imposto por uma dosagem dupla do herbicida imazaquin. No presente trabalho, verificou-se que a redução na germinação de sementes de plantas daninhas na testemunha com palha foi de até $22 \%$ para capim-colonião, $26 \%$ para capim-marmelada, 49\% para capim-colchão, 83\% para caruru e 90\% para capim-braquiária.

Todos os tratamentos em que se empregou o imazapic isolado ou em mistura proporcionaram redução no acúmulo de biomassa seca das plantas daninhas, tanto da total como da específica (Tabela 6), mostrando que a comunidade, assim como seus indivíduos, se desenvolveu pouco quando sob esses tratamentos. A biomassa seca acumulada nas duas testemunhas foi semelhante, demonstrando que a cobertura com palha não afetou de modo diferenciado o crescimento da comunidade e as plantas daninhas que a compõem, mas apenas a densidade. Como resultado da redução na biomassa seca total, verificou-se que o tratamento em que se empregou o imazapic sobre a palha (tratamento 2) foi mais eficiente que quando se aplicou o produto diretamente sobre o solo (tratamento 3). A aplicação da mistura de imazapic com pendimethalin (tratamento 4) resultou em excelente controle, superando assim os dois outros tratamentos. Essa diferença no controle deve-se basicamente ao escape do capim-braquiária (BRADC).

Pelos resultados obtidos nessas condições experimentais, pode-se concluir que uma camada de palha de cana-de-açúcar (var. SP79 1011) numa quantidade equivalente a $12 \mathrm{t} \mathrm{ha}^{-1}$ não interfere na ação do imazapic, tanto isolado como em mistura com pendimethalin, no controle de Panicum maximum, Brachiaria plantaginea, Digitaria horizontalis, Amaranthus viridis e Cyperus rotundus. Para Ipomoea grandifolia, a presença da palha reduziu a eficiência do produto. O imazapic se mostrou ineficiente para o controle de Brachiaria decumbens nas duas condições de cobertura do solo, e a adição de pendimethalin aumentou a eficiência do produto.

Conclui-se, também, que com o aumento no índice pluviométrico após a aplicação, de 30 para $90 \mathrm{~mm}$, ocorre visualmente o arraste do imazapic para maiores profundidades do Latossolo Vermelho-Escuro, podendo reduzir a eficiência do produto no controle das plantas daninhas presentes na camada superficial $(15 \mathrm{~cm})$ deste solo.

\section{LITERATURA CITADA}

AGRIANUAL 2001. São Paulo: FNP Consultoria, 2001. p.248-265. 
ARÉVALO, R.A.; BERTONCINI, E.I. Manejo químico de plantas daninhas nos resíduos de colheita de cana crua. STAB; Açúcar Álcool e Subp., v.17, n.4, p.36-38, 1999.

ASOCIATION LATINOAMERICANA DE MALEZAS. Recomendaciones de los sistemas de evaluacionen ensayos de control de malezas. ALAM, v.1, n.1, p.35-38, 1974.

CARLISLE, S.M.; TREVORS, J.T. Glyphosate in the environment. Water Air Soil Poll., n.39, p.409420, 1988.

FORNAROLLI, D.A.; RODRIGUES, J.; LIMA; VALÉRIO, M.A. Influência da cobertura morta no comportamento do herbicida atrazine. Planta Daninha, v.16, n.2, p.97-107, 1998.

KUVA, M.A.; PITELLI, R.A., CHRISTOFFOLETI, P.J., ALVES, P.L.C.A. Períodos de interferência das plantas daninhas na cultura da cana-de-açúcar. I - Tiririca. Planta Daninha, v.18, n.2, p.241251, 2000.

LORENZI, H. Plantas daninhas e seu controle na cultura da cana-de-açúcar. In: REUNIÃO TÉCNICA AGRONÔMICA COOPERSUCAR: PRAGAS DA CULTURA DA CANA-DE-AÇÚCAR, 1983, Piracicaba. Anais... São Paulo: COOPERSUCAR, 1983. p.59-73.

LORENZI, H. Tiririca, uma ameaça aos canaviais. B. Tec. Coopersucar, v.35, p.3-10, 1986.
NICHOLLS, P.H. Factors influencing entry of pesticides into soil water. Pest. Sci., n.22, p.123-137, 1988.

PITELLI, R.A. Interferência de plantas daninhas em culturas agrícolas. Inf. Agropec., v.11, n.129, p.16-27, 1985.

RODRIGUES, B.N.; ALMEIDA, F.S. Guia de herbicidas: contribuição para o uso adequado em plantio direto e convencional. 4.ed. Londrina, IAPAR, 1998. p.318-507.

RODRIGUES, B.N.; LIMA, J.; YADA, I.F.U.; ULBRICH, A.V.; FORNAROLLI, D.A. Influência da cobertura morta na retenção do imazaquin em plantio direto de soja. Planta Daninha, v.18, p.231-239, 2000.

SPRANKLE, P.; MEGGITT, W.F.; PENNER, D. Absorption, mobility, and microbial degradation of glyphosate in the soil. Weed Sci., v.23, n.3, p.229-234, 1975.

WEBER, J.B.; MILLER, C.T. Organic chemical movement over and through soil. In: SAWHNEY, B.L.; BROWN, K., eds. Reactions and movement of organic chemicals in soil. Madison: SSSA, 1989. p.305-334. (Special Publication, 22).

WEHTJE, G.; DICKENS, R.; WILCUT, J.W. Sorption and mobility of sulfometuron and imazapyr in five Alabama soils. Weed Sci., v.35, p.858. 1987. 